Cite as: Diriye, A. W., Jama, O. M., Diriye, J. W., \& Abdi, A. M. (2022).

Public preference for sustainable land use policies - Empirical results

from multinomial logit model analysis. Land Use Policy, 114, 105975.

DOI: https://doi.org/10.1016/j.landusepol.2022.105975

\title{
Public preference for sustainable land use policies - Empirical results from multinomial logit model analysis
}

\author{
Abdishakur W. Diriye ${ }^{a, b, d, 1}$, Osman M. Jama ${ }^{c, d, *, 2}$, Jama Warsame Diriye ${ }^{e}$, Abdulhakim M. Abdi ${ }^{\text {f, } 3}$ \\ a School of Public Affairs, University of Science and Technology of China, Hefei, People's Republic of China \\ ${ }^{\mathrm{b}}$ School of Geographical Sciences, University of Bristol, United Kingdom \\ ${ }^{\mathrm{c}}$ Department of Science and Technology of Communication and Policy, University of Science and Technology of China, Hefei, People's Republic of China \\ d Department of Public Administration, Faculty of Economics and Management Science, Mogadishu University, Mogadishu, Somalia \\ e Department of Environmental Science and Management, Faculty of Agriculture and Environment, Amoud University, Borama, Somalia \\ ${ }^{\mathrm{f}}$ Center for Environmental and Climate Science, Lund University, Sölvegatan 37, SE-223 62 Lund, Sweden
}

\section{A R T I C L E I N F O}

\section{Keywords:}

Public preferences

Sustainable land use policies

Policy instruments

Cultural worldviews

Multinomial logit model

\begin{abstract}
A B S T R A C T
Public preferences for sustainable land use policy instruments and the motivations behind such preferences are important to make appropriate policies. Based on survey data $(\mathrm{n}=309)$ from northeastern Somalia, we examined preferences for a set of land use policy instruments relative to no policy (i.e. the current status quo) and how cultural worldviews predict such preferences. We used a multinomial logit model to analyze the comparative evaluation of choices due to its interpretability and robustness to violations of normality. Overall, the results show that the respondents are likely to consent to all types of land use policy instruments relative to no policy and are more inclined to market-based and informational policy instruments. Specifically, preferences for regulatory policy instruments are positively associated with hierarchy and egalitarian worldviews and are negatively associated with fatalism and individualistic worldviews with only hierarchy and fatalism are significant. The market-based policy instrument is desirable to all cultural worldviews except fatalism, but only egalitarian and individual worldviews are significant. Preferences for informational policy instruments are positively associated with all cultural worldviews but only egalitarian worldviews showed a significant effect. Although there are some contradictions, these results are broadly consistent with the proposition of the cultural theory of risk. This study highlights that preferences for land use policies are heterogeneous with cultural worldviews mainly explaining the sources of this heterogeneity. It is evident that the respondents were willing to consent to land use policies relative to the status quo of no policy and indicates the need for concerted effort to reduce land degradation and deforestation in the country. We, therefore, recommend that policymakers incorporate the different ways that humans perceive and interpret social-environmental relations into policy decisions to achieve sustainable policy outcomes.
\end{abstract}

\section{Introduction}

Sustainable land use policies have become increasingly important over the last few decades to counter the detrimental effects of problematic land use and its causes (Lambin et al., 2014; Reinikainen et al., 2016). Globally, land degradation is a persistent environmental problem
(Batunacun et al., 2019; Omuto et al., 2011), and deforestation is a leading cause of land degradation which has brought attention, especially in Somalia (Bolognesi et al., 2015; Oduori et al., 2011). To counter such environmental conditions, an important aspect of a policy that becomes a phenomenon of interest is the choice of policy instrument (Böcher, 2012; Van Gossum et al., 2009). Policymakers can choose from

\footnotetext{
* Corresponding author at: Department of Science and Technology of Communication and Policy, University of Science and Technology of China, Hefei, People's Republic of China.

E-mail address: osmanjama@mail.ustc.edu.cn (O.M. Jama).

1 ORCID: http://orcid.org/0000-0001-7457-6828

${ }^{2}$ ORCID: http://orcid.org/0000-0002-7345-2812

3 ORCID: http://orcid.org/0000-0001-6486-8747
} 
regulatory policy instruments, such as land use zoning (Lambin et al., 2014), market-based policy instruments such as payments for environmental services (Alix-Garcia et al., 2018; Wunder et al., 2008), and informational instruments that attempt to induce voluntary action (Burstein, 2003).

The human sphere and its associated behavioral aspects play an integral role in policy choices. Therefore, policymakers need to choose policy instruments that can leverage collective social activities to achieve the intended policy outcome (Böcher and Töller, 2007). However, compliance with such behavioral and lifestyle changes often creates policy setbacks, as policy goals may be at odds with people's interests and values. This particularly applies to land use policies, as it has direct and visible impacts on livelihoods (Lambin et al., 2014). People can even resist more effective policies that increase their material merits (Cherry et al., 2017) because issues that seem to be merely factual to policymakers can be seen differently by the public (Rissman et al., 2017). Considering this, scholars are increasingly recognizing the importance of addressing public views on how to achieve desirable environmental and social outcomes when designing land use policies (Williams, 2014). Moreover, they suggest that the design of promising environmental policies requires exploring public preferences for alternative policy instruments (Valeri et al., 2016).

Previous studies show that preferences partially depend on the nature of the policy (Kemper et al., 2018; Pleger, 2017). Also, preferences for policy instruments are determined by the values and beliefs of affected people particularly, values that are defined by cultural worldviews play an integral part in how people assess and shape preferences for policies (Kahan and Braman, 2006). Cultural worldviews are socially constructed orientations that shape individual interpretations of environmental problems and their policy solutions. Recent empirical studies confirm the importance of the cultural worldviews influence on public preferences for various policy instruments (Kemper et al., 2018; Rissman et al., 2017). Based on their cultural worldviews, people may credit or neglect certain policies. Therefore, crafting policies that can reflect the acceptable social means of individuals with different cultural worldviews is challenging (Kemper et al., 2018). In this regard, Markle (2019) highlighted the need to design culturally targeted policies to achieve desirable environmental and social outcomes. However, the best way to design such targeted policies is not yet sufficiently emphasized in previous studies.

This study investigated preferences for a set of land use policy instruments namely, land use zoning, payments for environmental services, and environmental education, relative to no policy (i.e. the current status quo) in northeastern Somalia using a multinomial logit model. More specifically, this study examined whether a high degree of alignment between the specific cultural worldviews and policy types can predict preferences for policy instruments by drawing insights from instrument choice and the cultural theory of risk. The proposed policies were described in terms of their characteristics and definitions of the key terms using information from the previous studies (Borrás and Edquist, 2013; Lambin et al., 2014; Wunder et al., 2008) to give the respondents a clear idea of how these policies work and will impact on their environmental practices before asking to make the choices. Also, the preferences were captured by asking the respondents to choose their most preferred option within four different close-ended multiple choices. The aim was to examine whether each cultural group prefers only the policies that are consistent with their commitments or choose different policy types.

This paper is organized as follows: Section 2 reviews the literature using cultural worldviews and the instrument choice theory. Section 3 illustrates the method and gives a brief description of the study area. Section 4 presents the results of the empirical analysis. Section 5 includes interpretations and discussion of the results as well as policy implications and study limitations. Section 6 presents our concluding remarks.

\section{Theoretical framework}

\subsection{Instrument choice theory}

Policy instruments are defined as a "set of techniques through which policymakers exercise their authority to facilitate and effect change in society" (Vedung et al., 1998). Policy instruments differ based on their mechanisms to shape collective social action and can be classified as regulatory, market-based, and informational instruments (Böcher, 2012; Böcher and Töller, 2003).

Land use has historically been managed using regulatory or command and control instruments that emphasize restrictions, approvals, and if necessary penalties, and include the implementation of zoning and the establishment of protected areas (Lambin et al., 2014). While these policies have been commonly known to reduce deforestation (Bruggeman et al., 2015, 2018), critics have charged that they cause uncompensated costs for people, spill over effects beyond the authorities, and are overly expensive to be implemented (Gunningham and Sinclair, 2003; Lambin et al., 2014). Alternatively, market-based instruments that use incentives, price signals, and other mechanisms to facilitate behavioral changes have been developed and implemented (Jordan et al., 2003; Lambin et al., 2014). These approaches include payments for environmental services (PES), eco-certification, and many others (Lambin et al., 2014). PES, for instance, became a preferred policy solution in many low-income contexts because of its potential to reconcile conservation and livelihood goals (Sims and Alix-Garcia, 2017) and has been regarded as more appropriate for communal land tenure settings (Kaczan et al., 2017) such as Somalia. Furthermore, informational policy instruments rely on voluntary actions by raising awareness, but these policies can suffer from free riders and persistent, irrational actors (Kaczan et al., 2017). Considering this, scholars argue that regulatory instruments are often still effective and required (Cole and Grossman, 2002). and, many countries remain dependent on direct state control in their environmental policies (Makrickiene et al., 2019).

The choice of which policy instrument to enact is commonly based on the instrument selection criteria, which often rely on the competing values of efficiency, effectiveness, legitimacy, legality, and democracy (Vedung et al., 1998). Here, preference comes under the legitimacy value of the instrument selection criteria. Although a sustainable environmental condition is a common interest (Lasisi et al., 2021; Malik et al., 2019), people prefer to accept different policy instruments. For example, (Rissman et al., 2017) found high support for regulatory and market-based water quality policies and relatively low support for policies that rely on voluntary action. Likewise, Stadelmann-Steffen (2011) found that people favor climate change policies involving restrictions and prohibitions over market-based policy approaches. On the contrary, de Groot and Schuitema (2012) and Pleger (2017) observed that citizens prefer land use and environmental policy instruments that reward good behaviors rather than punishing undesirable practices. This lack of scientific consensus and the absence of similar studies in Somalia justify empirical studies to examine which policy instruments will most likely succeed in the country.

\subsection{The cultural theory of risk}

The cultural theory of risk also referred to as "the theory of sociocultural viability," was first developed by British anthropologist (Douglas, 1970) and has been further revised by other scholars over the last five decades (Douglas and Wildavsky, 1983; Wildavsky, 1987). The theory provides an essential framework for identifying and addressing different views on environmental issues that generate divisive public discourse (Leiserowitz, 2006; O'Riordan and Jordan, 1999).

The theory is based on 'grid-group' dimensions. On one hand, the 'group' represents the extent to which a person is embedded and dedicated to a group or social system termed "high group," versus the extent to which a person becomes a self-centric and feels little sense of unity 
and is characterized as "low group" (Thompson et al., 1990). On the other hand, the 'grid' describes the extent to which a person's thoughts and behaviors in social relations are governed by social rules and norms termed "high grid" versus the extent that people determine changes in the norms they live and are referenced as "low grid" (Thompson et al., 1990). In other words, (Wildavsky, 1987) states 'the group dimension answers "who am I?" or "who am I with?" and the grid answers "how should I behave?

The theory postulates that these two dimensions result in four cultural biases, often called "cultural worldviews" (Thompson et al., 1990). The cultural biases of individualism, fatalism, hierarchy, and egalitarianism are values that justify different perceptions and preferences regarding environmental issues and social relations. These include how humanity and nature are viewed, risks are perceived, preferences for management strategies, and other normative ideals. For example, individualism asserts a low degree of both grid and group; fatalism asserts high grid and low group; hierarchy is a high degree of both group and grid, and egalitarianism is a high grid and low group (Thompson et al., 1990).

Each cultural bias compensates for alternative interpretations of how we must live with one another and with nature and offers some wisdom elements that others lack. First, in an egalitarian setting, nature is perceived as ephemeral, existing in a delicate and precarious balance; therefore, it should be treated with respect and protected from human carelessness (Dake, 1992). This cultural bias frames humanity as principally altruistic and stresses the importance of living and acting together (Wildavsky, 1987). Voluntary simplicity is preferred as an answer to environmental issues, and externally imposed controls and restrictions on choice are resisted. Second, members of the hierarchy view nature as almost stable and resilient, but only within limits, and if it is pushed beyond its limits, it can result in a complete collapse of nature (Schwarz and Thompson, 1990). Humanity is viewed as imperfect unless regulated by firm top-down institutions (O'Riordan and Jordan, 1999), and strict rules and regulations are preferred to preserve the balance of nature (Wildavsky, 1987). Anyone who does not obey the law is considered guilty (Mamadouh, 1999). The government and experts are seen as responsible for regulating human-environment relations (Schwarz and Thompson, 1990). Third, individualists are driven by personal interests and self-autonomy ideals (O'Riordan and Jordan, 1999), and nature is framed as benign. Resources are unlimited, robust, and stable to recover from any exploitation; therefore, improving economic opportunities is preferred as an answer to environmental issues. Finally, in fatalist discourses, nature is framed as capricious, where fate essentially dictates events (Schwarz and Thompson, 1990), and humanity is seen as unfair (O'Riordan and Jordan, 1999). Inaction and permission are justified, and policy preferences vary (Dake, 1992).

Literature on the cultural theory of risk shows that the four cultural biases result in four policy preferences. Given this, cultural theorists predict that policy intervention is more likely to fail without giving recognition to all of these biases (Hartmann, 2012; Verweij et al., 2006) and argue that consensus is achievable only when all cultural biases other than fatalists are involved in policy decisions (Thompson et al., 1990). A large number of empirical studies have tested the theory in various contexts and confirmed the patterns of environmental perceptions and policy preferences that it suggests (Kemper et al., 2018; Markle, 2019; Rissman et al., 2017). For example, people who describe themselves as individualists are found to prefer market-based policies (Markle, 2019; Rissman et al., 2017), and a hierarchical worldview is associated with beliefs that government should implement strict rules and regulations to govern the environment (Markle, 2019). Although the relationship may be weak in regulatory policies, egalitarian world views are positively related to different environmental policies (Rissman et al., 2017). Given this situation, policymakers are confronted with making policies consistent with different cultural worldview preferences (Kahan and Braman, 2006). However, the majority of the available studies have been conducted in generally developed Western world (Xue et al., 2014). There is thus a strong rationale for evaluating generalizability of this framework through research based in other parts of the world.

\section{Materials and methods}

\subsection{Land degradation and deforestation in the study area}

This study was carried out in Puntland (Fig. 1), which is the northeastern state of Somalia. Puntland borders the Gulf of Aden to the north, Ethiopia to the southwest, the Indian Ocean to the east, and Somaliland to the west. The region has an arid and semi-arid type of climate with low seasonal average precipitation $(180 \mathrm{~mm})$ where droughts occur every 2-3 years followed by floods (Unep, 2005). The crop production and pasture for livestock in this area are dependent on rainfall (Omuto et al., 2011). The area is experiencing severe land degradation and is a highly deforested area (Oduori et al., 2011; Omuto et al., 2011). Deforestation causes various negative impacts, including loss of vegetation cover and soil erosion (Oduori et al., 2011; Omuto et al., 2011). A study in the region (Oduori et al. (2011) showed an estimated $2.8 \%$ of annual tree loss between 2001 and 2006. Consequently, loss of vegetation results in reduced livestock numbers, which threatens livelihood opportunities, deepens poverty, and in turn results in famine (Waaben Thulstrup et al., 2018).

The main trigger of deforestation in this region is not only the local charcoal demand for cooking and heating (Bolognesi et al., 2015; Oduori et al., 2011) but also foreign exports, which account for $80 \%$ of charcoal production in Somalia (Unep, 2005). The charcoal is exported to middle east countries such as Yemen, the United Arab Emirates, Saudi Arabia, and Iran (Unep, 2005), and this business became a main source of revenue for Al-Shabaab which makes it a threat to security (Rembold et al., 2013). Considering this, the United Nations Security Council issued a ban on charcoal exports from Somalia in 2011 (UNDP, 2012). Likewise, the federal and regional governments of Somalia issued series of prohibitions on deforestation and charcoal exportation. Despite these interventions, there is still significant concern on charcoal export and a need for government action (Bolognesi et al., 2015; Waaben Thulstrup et al., 2018). Since land use policies directly impact livelihoods, understanding citizens' preferences for a set of policies may help the government to propose appropriate policy interventions.

\subsection{Preference and choice models}

Preference is described as the response when people are asked to make a comparative evaluation of a choice set such as the source of energy that should be used (Van Rijnsoever et al., 2015). Such choice experiment method is suitable for examining stated preferences for environmental changes, such as land use policies (Grammatikopoulou et al., 2020), and offers some advantages in the valuation of shared goods and services for which there is no clear price index (Bateman et al., 2002). In this method, the respondents are exposed to a range of options described by preselected characteristics and are told to choose their most preferred choice (Hensher et al., 2005). An economic attribute reflecting the cost of the option and status quo alternative representing free-cost or 'no change' situation as the baseline is often included in the choice set. In the stated preference studies, it is commonly accepted that researchers should support respondents' preference formation by giving information instead of relying on their existing knowledge (Carson, 2000). Increasing the knowledge levels of respondents can affect the choice outcome as well as the nature of the outcome (Tisdell and Wilson, 2006). Besides, it is highlighted the importance of making sure that the choice descriptions are "comprehensible, reasonable and meaningful" to the respondents, to obtain reliable results (Mitchell et al., 1989). This makes the survey respondents face a trade-off between desired outcomes and the cost of having these outcomes and such a result informs policy designs. 


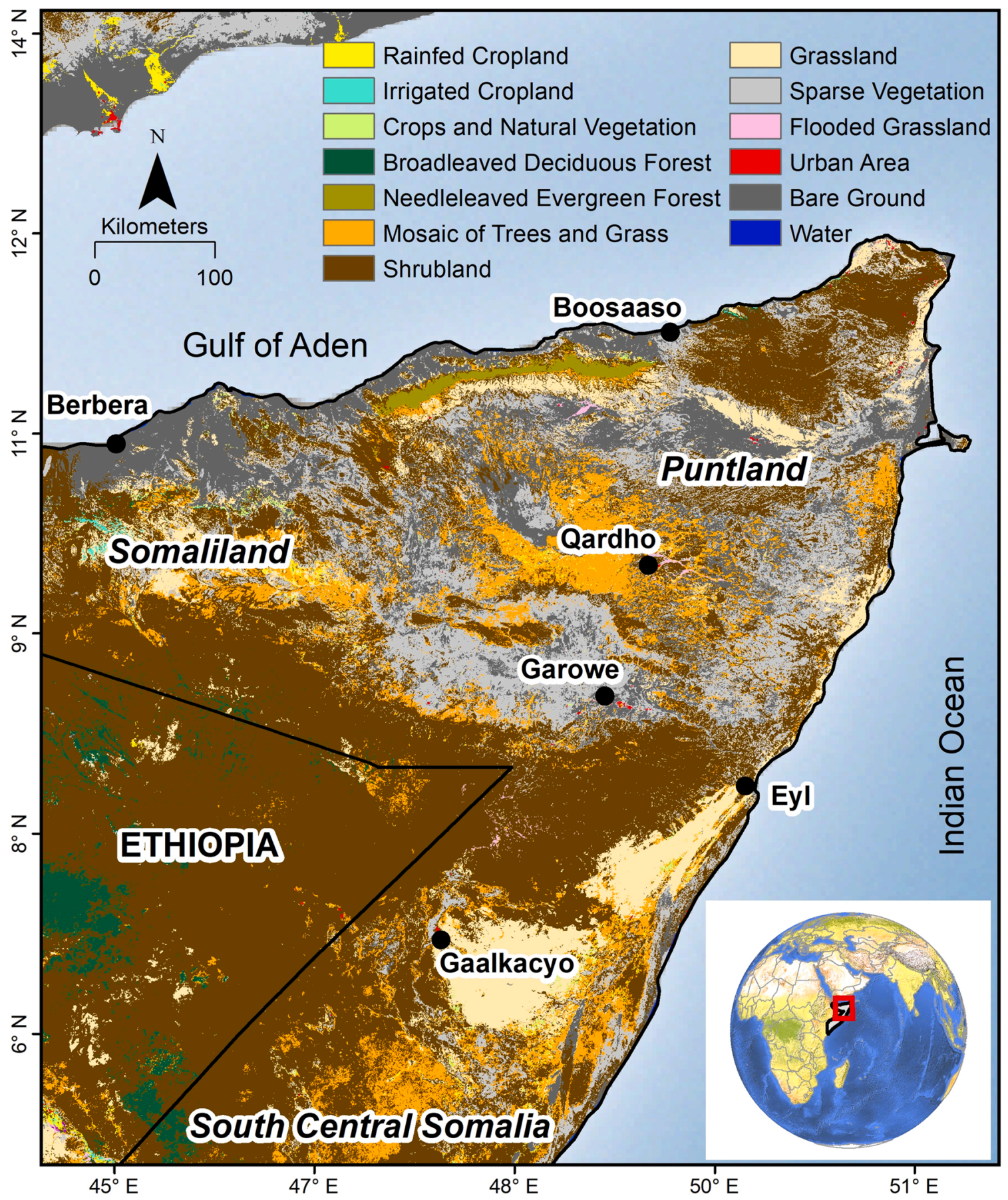

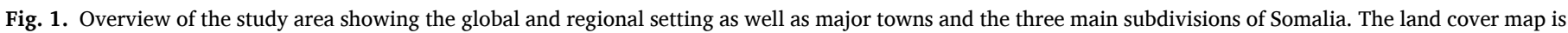
based on the European Space Agency's Climate Change Initiative Land Cover, 2020.

Choice experiment methods have been widely applied for studying preferences for different policy areas such as climate change mitigation and biodiversity conservation (Shoyama et al., 2013), forest management (Upton et al., 2012), and agri-environmental issues (Grammatikopoulou et al., 2020), and this study aims to contribute to these studies from an angle that focuses on the motivations behind these preferences.

\subsection{Survey and respondents}

A survey questionnaire was distributed to a representative sample of Somali citizens living in Puntland in May 2020 using a well-known online platform for data collection (www.jotform.com). We used the
Global Positioning System (GPS) to collect data from residents of the study area by choosing always on-location from the online data collection platform. An online survey was justified as the primary datagathering tool because of its advantages in saving time, fewer errors in data entry, and accessibility for the target population (USAGM, 2013). Still, hard copies were distributed to respondents in areas where internet access was low to ensure adequate representation of different geospatial areas. The G*Power Software program was used to estimate the sample size in prior power analysis with an estimated population effect size (f2) of 0.5 , the conventional desired power of 0.8 , the customary alpha level of 0.05 , and the number of the predictors in the study (4). The minimum number of respondents required for the study is 168 . We received 449 
responses, of which 309 responses were valid for the actual analysis. To ensure the actual representation of the policy addressees, the respondents were mainly mature in age and understood the general importance of forests and land.

The survey was pre-tested with 30 volunteer participants of different professions, age groups, genders, and education levels and was designed in three parts. The first part identified respondents' demographic information such as gender, age, educational level, personal income, and residential area. The second part measured respondents' cultural worldviews on a Likert scale of five-point ranging from strongly disagree (1) to strongly agree (5) using 16 items from Price, Walker, and Boschetti (Price et al., 2014)'s cultural group measurements. See Appendix 1 . These items were tested and validated across various samples and are considered as robust measures of cultural worldviews (Halik and Verweij, 2018; Price et al., 2014). The third part identified the participants' policy preferences.

\subsection{The theoretical and empirical model}

Citizens' choices of policy instrument options were evaluated using a random utility theory-based model to capture the determinants of policy preferences. The random utility is warranted for the study as the preferred policy alternatives have no natural ordering and the relationship between the unobservable or the latent variable and the observed outcome is probabilistic. The random utility theory assumes that a person facing a choice over a list of options chooses an alternative that pays the maximum utility (Hensher et al., 2005). Based on this assumption, respondents are likely to choose the policy instrument option, which gives the perceived maximum utility compared to other alternatives in the choice list. The utility function can be decomposed into random or unobservable components and observable or systematic components. Assuming that $\mathrm{u}_{\mathrm{m}}$ and $\mathrm{u}_{\mathrm{j}}$ represent the utility of citizen í, who decides on between any two options, the equation of the random utility can be described as

$\mathrm{U}_{\mathrm{i} m}=\mathrm{V}_{\mathrm{i} m}+\varepsilon_{\mathrm{i} m}$

where $u_{i m}$ is the utility of alternative $m$ for individual $i, v_{i m}$ is the observable component of the utility function and $\varepsilon_{\mathrm{ij}}$ is the unobservable component or the stochastic element of the utility. The error term or random component of the utility is assumed to be independently and identically distributed (McFadden, 1974). Here, the utility $V_{i m}$ is determined by a vector $x$ (e.g., cultural worldviews), i.e., $V_{\mathrm{im}}=\chi_{\mathrm{im}} \beta$ is a function of deterministic or observable elements of options.

Although residents consider a range of relevant factors in their choices and choose the option based on their utility, the utility $V_{\text {im }}$ is not observed directly. What is observable though are the choices citizens make and the influence of the stated attributes in response to policy instrument options. Therefore, the choices are probabilistic and the probability of a person preferring to choose option i from a list of policy alternatives can be given as

$$
\begin{aligned}
& \mathrm{P}_{i m}=\operatorname{Pr}\left[f_{0}\right)\left(\mathrm{u}_{i m}>\mathrm{u}_{\mathrm{ij}}\right) \forall \mathrm{m} \neq \mathrm{j} \\
& =\operatorname{Pr}\left(\mathrm{u}_{i m}+\varepsilon_{i m}>\mathrm{u}_{\mathrm{ij}}+\varepsilon_{\mathrm{ij}}\right) \forall \mathrm{m} \neq \mathrm{j} \\
& =r\left(\mathrm{u}_{i m}-\mathrm{u}_{i j}>+\quad \varepsilon_{\mathrm{ij}}+\varepsilon_{\mathrm{im}}\right) \forall \mathrm{m} \neq \mathrm{j}
\end{aligned}
$$

Based on different assumptions, several models can be employed in the context of this study. However, the assumed distribution of the random disturbance terms leads to the multinomial logit (MNL) model. The MNL is justified for the study because the participants employ a comparative evaluation to choose among a dependent variable that has multiple outcomes that are not naturally ranked or ordered in terms of their relative importance. Assume that the dependent variable (y) in this study has $\mathrm{M}$ outcome categories i.e., land use zoning, payments for environmental services, environmental awareness, and status quo ( $\mathrm{y}_{1}$,
... $\left.\mathrm{y}_{\mathrm{M}}\right)$, which is determined by a vector of $\mathrm{K}$ explanatory variables i.e., cultural worldviews, $\mathrm{x}=\left(\mathrm{x}_{1}, \ldots \mathrm{x}_{\mathrm{k}}\right)$ with their corresponding set of parameters or regression coefficients $\beta\left(\beta_{0 j}, \ldots . \beta_{\mathrm{kj}}\right)$. The probability of an individual í choosing option $\mathrm{j}$ from the list of $\mathrm{M}$ options is equal to the exponential of the observed utility index for option $j$ to the sum of the exponentials of the observed utility indices for all $\mathrm{M}$ options including the í-th option (Hensher et al., 2005).

$\operatorname{Pr}(\mathrm{y}=\mathrm{j} / \chi)=\frac{\exp \left(\mathrm{f}_{(0)}(\chi \beta \mathrm{j})\right.}{1+\sum_{m=1}^{m} \exp [(\chi \beta \mathrm{m})}$

Coefficients $\left(\beta_{0 \mathrm{j}}, \ldots . \beta_{\mathrm{kj}}\right)$ can be estimated using a multinomial logistic regression (MNL) model to determine the effect of the explanatory variables on the probability choices. The estimated coefficients of the predictor variables indicate only the direction of effects rather than the degree of the effect or probabilities; thus, the odds ratios are estimated and interpreted along with their significance level. The odds ratio represents the likelihood of choosing an outcome compared to the base category, as the model assigns one dependent outcome as the reference or base category and then the odds of choosing other categories are compared to the odds of choosing the reference category. If the odds ratio is greater than one, it denotes that the odds ratio is positively related to the increased chance of the choices relative to the base category, and the decimal point odds represent the exact opposite. The MNL is built on the assumption of independence of irrelevant alternatives (IIA), which asserts that omitting or adding an outcome category should not affect the other categories' odds ratio. In other words, the likelihood of choosing one outcome should not be affected by the addition or omission of an outcome category.

\section{Results}

\subsection{Descriptive results}

A total of 449 responses were yielded and after scrutiny, 140 responses were discarded for some reasons such as inconsistency and incompleteness leaving 309 valid responses available for analysis with a response rate of $56 \%$. The socio-demographic characteristics of the respondents are presented in Table 1 . Male $(57.3 \%)$ were slightly more than the female (42.7\%). In terms of residential areas, $51.8 \%$ were living in major cities, $33 \%$ in towns, and $15.2 \%$ in rural areas, and in terms of educational attainment, $20.1 \%$ completed high school, $52.8 \%$ bachelor degree, $24.6 \%$ master and $2.6 \%$ doctoral studies. The mean monthly income was approximately $\$ 250$. This sample represents a regional population with a slightly higher response rate among young, educated men. However, there is no significant difference between the population and the sample mean across age, as $75 \%$ of the Somali population is

\begin{tabular}{|c|c|c|c|c|}
\hline Variables & Coding & Percentage \% & Mean & Std. Dev. \\
\hline \multirow[t]{2}{*}{ Gender } & $1=$ Female & 42.7 & 1.573 & .495 \\
\hline & $2=$ Male & 57.3 & & \\
\hline \multirow[t]{4}{*}{ Age group } & $1=$ Below 20 & 8.4 & 2.489 & .771 \\
\hline & $2=20-30$ & 43.0 & & \\
\hline & $3=31-40$ & 39.8 & & \\
\hline & $4=$ Above 40 & 8.7 & & \\
\hline \multirow[t]{4}{*}{ Educational level } & $1=$ High school & 20.1 & 2.097 & .737 \\
\hline & $2=$ Bachelor & 52.8 & & \\
\hline & $3=$ Masters & 24.6 & & \\
\hline & $4=$ Doctoral studies & 2.6 & & \\
\hline \multirow[t]{3}{*}{ Residential area } & $1=$ City & 51.8 & 1.634 & .733 \\
\hline & $2=$ Town & 33.0 & & \\
\hline & $3=$ Village & 15.2 & & \\
\hline \multirow[t]{4}{*}{ Personal income } & $1=$ Less than $\$ 150$ & 36.2 & 2.058 & 1.005 \\
\hline & $2=\$ 150-\$ 300$ & 33.0 & & \\
\hline & $3=\$ 300-\$ 450$ & 19.4 & & \\
\hline & $4=$ Above $\$ 450$ & 11.3 & & \\
\hline
\end{tabular}

Table 1

Socio-demographics of the sample $(n=309)$. 
under the age of 30 (UNFPA, 2014). The effect of socio-demographic factors was controlled, as they were not significant preference predictors across different policies.

\subsection{Model fitness}

Various indicators of model fitness were checked using the STATA software program version-16, which indicated that the model was fit and appropriate to public preferences for land use policy instruments. For example, the estimated value of the likelihood ratio (chi-square $=$ $271.445, \mathrm{P}=.0000$ ) suggests that the predictive power of the model is reasonable; therefore, the null hypothesis that all independent variables in this model do not jointly differ from zero is rejected at $10 \%$ (Table 2). Additionally, the McFadden pseudo R2 $=0.396$ suggests that the estimated model outperforms the nonexistent model by $40 \%$ and hence has strong predictive power (Table 2). The IIA assumption was checked by the Hausman-McFadden test and the probability values ( $P>$ chi2) of the test results ranged from 0.874 to 1.00 , which supports the null hypothesis that policy instrument options are independent of one another (Table 2). The Wald and Likelihood ratio tests indicate that each explanatory variable is a significant predictor (Table 3). Finally, the relative importance of the policy options is assessed using predicted probabilities (Fig. 2). The least preferred option was no policy "status quo"; therefore, it was designated as the base category. The probability of choosing other policy alternatives is then compared to the probability of choosing no policy to examine whether and how strongly people value implementing new policies and consent to a high level of land preservation over the status quo.

\subsection{Econometric results}

Cultural worldviews were found to be significant predictors of policy preferences. Table 2 presents the MNL model results, where each column shows a different model. An increase (one-unit from 1 to 5 ) in egalitarianism increases the relative risk of preferring informational and market-based policy instruments relative to no policy "the status-quo" by 4.85 and 4.22 , respectively. While it is not significant, egalitarianism also increases the likelihood of choosing regulatory policy instruments relative to no policy by 1.617 . (See Table 4 and Fig. 3).

An increase in hierarchy increases the relative risk of preferring regulatory policy instruments relative to no policy instrument as a base category by 5.003 . Although it is negligible, hierarchy increases the relative risk of favoring market-based and informational policy instruments as opposed to no policy instrument as a base category by 1.35 and 1.311 respectively. (See Table 4 and Fig. 4).

An increase in individualism increases the relative risk of preferring market-based policy instruments relative to no policy by 8.188 . While the relationship is negligible, individualism is positively related to informational policy instruments preferences as opposed to no policy by 1.098 and negatively associated with regulatory policy instruments relative to no policy by .322 (See Table 4 and Fig. 5).

An increase in fatalism reduces the relative risk of preferring regulatory policy instruments as opposed to no policy by 0.206 . Although the effect of fatalism on the preference of the other policy instruments is negligible, it is positive in informational policy instruments (1.036), and

Table 2

Hausman tests of IIA assumption Ho: Odds (Outcome-J vs Outcome-K) are independent of other alternatives.

\begin{tabular}{lllll}
\hline Omitted & chi2 & Df & P > chi2 & Evidence \\
\hline No policy & 0.029 & 10 & 1.000 & For Ho \\
Info policy & 5.245 & 10 & 0.874 & For Ho \\
Market policy & -2.662 & 10 & 1.000 & For Ho \\
Regulatory policy & 3.045 & 10 & 0.980 & For Ho \\
\hline
\end{tabular}

Info is abbreviated from informational.
Table 3

Likelihood-ratio and Wald tests for independent variables.

\begin{tabular}{|c|c|c|c|c|c|c|}
\hline \multirow[b]{2}{*}{ Explanatory variables } & \multicolumn{3}{|c|}{ Wald tests } & \multicolumn{3}{|c|}{ Likelihood-ratio tests } \\
\hline & chi2 & Df & $\mathrm{P}>$ chi2 & chi2 & Df & $\mathrm{P}>$ chi2 \\
\hline Egalitarianism & 14.946 & 3 & 0.002 & 40.117 & 3 & 0.000 \\
\hline Hierarchy & 11.856 & 3 & 0.008 & 61.816 & 3 & 0.000 \\
\hline Individualism & 65.858 & 3 & 0.000 & 136.610 & 3 & 0.000 \\
\hline Fatalism & 30.980 & 3 & 0.000 & 22.212 & 3 & 0.000 \\
\hline
\end{tabular}

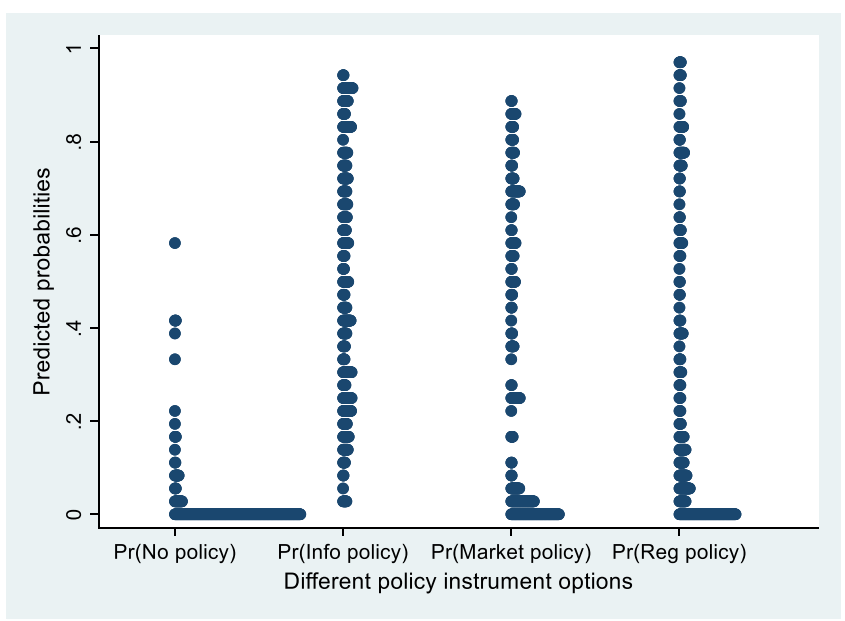

Fig. 2. Predicted probabilities of the different policy preferences. Notes: $p r$ means probability, info means informational and reg means regulatory.

Table 4

Relative risk ratios (rrr) of the multinomial logit model for policy preferences.

\begin{tabular}{|c|c|c|c|c|c|c|}
\hline \multirow[t]{2}{*}{ Variable names } & \multicolumn{2}{|c|}{$\begin{array}{l}\text { Informational } \\
\text { policy }\end{array}$} & \multicolumn{2}{|c|}{$\begin{array}{l}\text { Market-based } \\
\text { policy }\end{array}$} & \multicolumn{2}{|c|}{ Regulatory policy } \\
\hline & rrr & se & rrr & se & rrr & se \\
\hline Constant & .025 & .087 & $0 * * *$ & 0 & 3.38 & 12.856 \\
\hline Egalitarianism & $4.852^{* * *}$ & 2.874 & $4.22 * *$ & 2.663 & 1.617 & 1.019 \\
\hline Hierarchy & 1.311 & .795 & 1.35 & .873 & $5.003 * *$ & 3.512 \\
\hline Individualism & 1.098 & .697 & $8.188^{* * *}$ & 5.52 & .322 & .228 \\
\hline $\begin{array}{l}\text { Fatalism } \\
\text { Diagnostics }\end{array}$ & 1.036 & .772 & .919 & .704 & $.206^{* *}$ & .16 \\
\hline \multicolumn{3}{|c|}{ Base category $=$ no policy } & \multicolumn{4}{|c|}{$\begin{array}{l}\text { LR }(\text { chi-square })=271.445 \\
(P=.0000)\end{array}$} \\
\hline \multicolumn{3}{|c|}{$\begin{array}{l}\text { Number of obs }=309 \\
\text { Log likelihood }=-207.36863\end{array}$} & \multicolumn{4}{|c|}{ Pseudo R2 $=0.396$} \\
\hline
\end{tabular}

Notes: ${ }^{* * *} p<.01, * * p<.05, * p<.1$ respectively. se denotes standard error and rrr stands for relative risk ratio.

negative in market-based policy instruments (0.919). (See Table 4 and Fig. 6). Although there are some contradictions, these results are broadly consistent with the proposition of the cultural theory of risk.

\section{Discussion}

Understanding public preference for policy instruments is critical in shaping policy choices to achieve sustainable policy outcomes. Our findings provide further evidence that cultural worldviews play an important role to predict policy preferences in line with previous studies (Kemper et al., 2018; Rissman et al., 2017), and establish that the likelihood of approving the implementation of land use policies relative to no policy "status quo" is high in Somalia which may be a signal of public consent to ensure land use conditions at higher levels of conservation and may stress a need for government action. This may be prompted by the visibility of shrinking land resources in the country because when people feel that the problem is severe and deteriorating, 


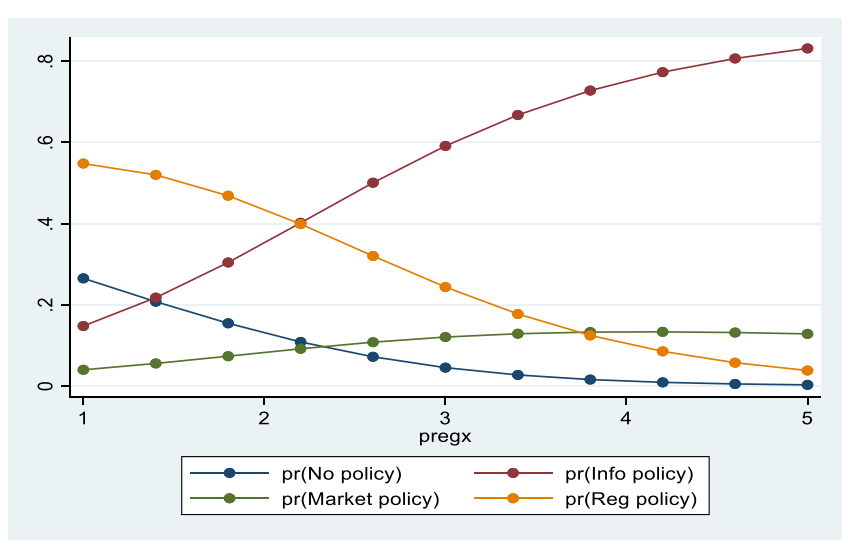

Fig. 3. The egalitarian worldview policy preferences. As the probability of being egalitarian increases, the preference for informational policy increases at a higher rate, and market-based policy increases at a lower rate whereas, the preference for both regulatory and no policy options decrease. Notes: pregx denotes the probability of egalitarian.

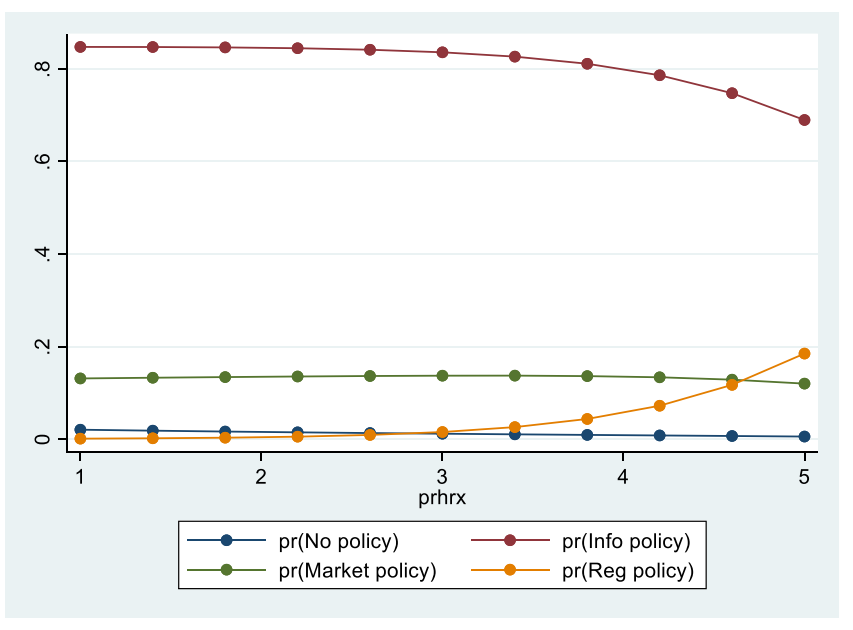

Fig. 4. The hierarchical worldview policy preferences. As the probability of being hierarchical increases, the preference for regulatory policy increases while at the same time the preference for informational policy decreases. Other policy options seem to be constant thought-out the process. Notes: prhrx denotes the probability of being a hierarchy.

they are more likely to make environmentally friendly decisions (Bayard and Jolly, 2007). Predicted probabilities graphically depict this finding (Fig. 2). Although people tend to prefer different policy instruments as outlined by the cultural theory of risk, there are areas of common interest as we discuss below, which may be promising for policymakers attempting to design policies that can appeal to people with different cultural worldviews.

Although preferences for informational policy instruments are positively associated across all cultural worldviews, it is relatively more desirable to the egalitarians. One possible cause for this approval could be due to previous policy experiences. Somalia has had a long history of authoritarian governance with top-down policies, which have often oppressed individual freedom and disturbed traditional communal systems. The current post-conflict federal system, which shifts previous hierarchical policies to a democratic and participatory approach, may induce a positive stance on informational policies. Also, access to information through seminars and workshops with no feedbacks where the participants receive monetary incentives is the only participation form of the environmental decision making in Puntland (Jama et al., 2020), therefore expectations of similar incentives or material benefits

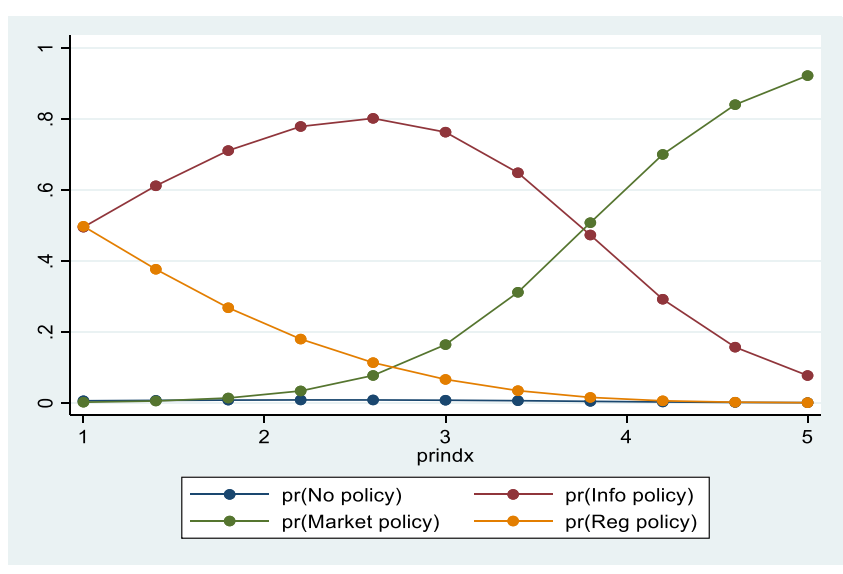

Fig. 5. The individualist worldview policy preferences. While there is no relationship between individualism and no policy option, as the probability of being individualist increases, the preference for market-based policy increases, and the preference for regulatory policy decreases. The preference for informational policy increases when individualism is at a low level whereas it decreases when individualism is at an extreme level. Notes: Prindx denotes the probability of an individual being individualist.

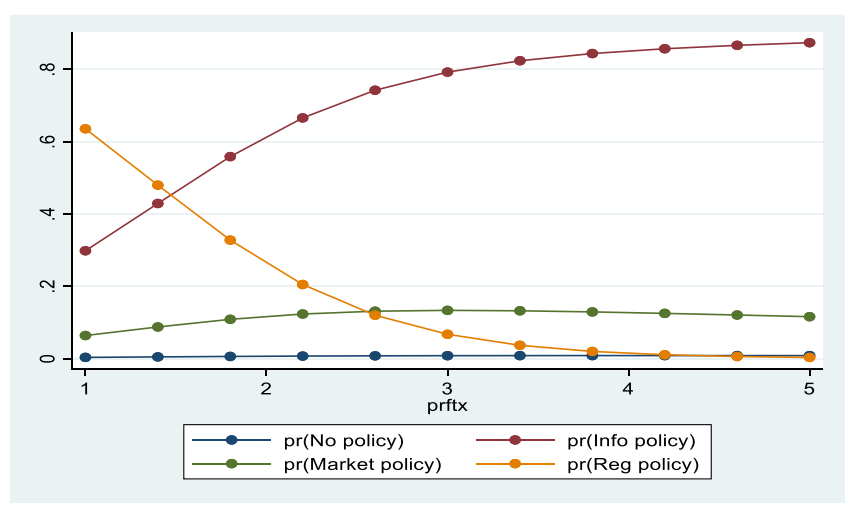

Fig. 6. The fatalist worldview policy preferences. While fatalism does not significantly affect market-based policy and no policy option, as the probability of being fatalism increases, the preference to informational policy increases, and the preference to regulatory policy decreases. Notes: prftx denotes the probability of being a fatalist.

may prompt preference for informational policy instrument. Still, this finding contradicts previous findings in the US context that residents expressed opposition to policies that rely on voluntary actions without government involvement (Rissman et al., 2017). Future research may examine whether preferences for policy choices are consistent across countries and whether it's influenced by the experience of different political-administrative systems.

Market-based policy instruments received relatively higher inclination from individualist and egalitarian worldviews. Although the relationship is weak, marker-based policies are also positively associated with a hierarchical worldview. This finding means that market-based policy instruments are highly desirable to the public which is consistent with previous studies that demonstrated higher acceptance and support for market-based policy approaches (Pleger, 2017; Rissman et al., 2017). Cultural theorists argue that members of the fatalist worldview are opportunistic; hence they take advantage of the resources that come their way. However, contrary to what one would expect based on such arguments, fatalism is negatively related to market-based policy instruments in our findings. This inconsistency may be prompted by skepticism and lack of trust in politicians because fatalist discourse frames humanity as unfair (O'Riordan and Jordan, 1999). Furthermore, 
our findings showed that individualists prefer informational and market-based policies relative to no policy "status-quo" which supports similar findings in earlier studies. Notably, Rissman et al. (2017) showed that individualists support carrot policies, and Markle (2019) indicated that individualists believe that free-market strategies are the way out to environmental problems but attribute the price to solve environmental issues to those responsible. This means that being an individualist does not evade the support of every policy and hence the differential effects of individualism across different policies should be examined rather than using aggregate policy.

Regulatory policy instruments gained a relatively higher preference from a hierarchical worldview, which is in line with earlier findings (Kemper et al., 2018). While the relationship is weak, the findings suggest that regulatory policy instruments also gain inclination from egalitarians. However, unlike informational and economic policies, regulatory policy instruments are negatively associated with and are less preferable to individualists and fatalists. As we explicitly mentioned policy characteristics in the survey, the perceived risk of individual autonomy may cause this aversion. Regulatory policies are more likely to be taken as a threat to individual autonomy, economic growth, and social well-being (Kahan and Braman, 2006). This finding means that regulatory policies may come across potential policy setbacks from specific segments of the people and may therefore require efforts to make it agreeable to the public. One way of making regulatory policies reflect acceptable social means is employing persuasive messages.

\subsection{Policy and practical implications}

Somali citizens are open and willing to consent to land use policies relative to no policy "the status quo", and while various land use policies seem to be desirable in Somalia, people are more inclined to marketbased and informational policies when selecting different policies. This may indicate the need for government action to reduce deforestation and land degradation in the country. Preferences for land use policy instruments are heterogeneous with cultural worldviews mainly explaining the sources of this heterogeneity. This means that each policy type resonates with certain population segments and neglects others meaning that one instrument type is insufficient to augment significant approval from individuals of diverse cultural worldviews which indicates the challenge of making policies consistent with the different rationales provided by the different cultural biases which have also been voiced in previous studies (Kahan and Braman, 2006); therefore, this knowledge is to be considered when designing future land use policies. Addressing public views on how to achieve desirable environmental and social outcomes when designing land use policies is deemed to help in efforts to attain sustainable land use policy outcomes (Williams, 2014). Thus, public preference is to be seen as complementary responses, and the patterns of the diverse cultural worldviews should necessitate bringing different perspectives to the center of policy debate to craft policies that can portray socially acceptable means for people with different cultural worldviews which means mediating the differences and seeking areas of common interest. Although there are important differences, this research establishes that there is common ground for efforts to dispel differences and promote holistic preferences. In this regard, hierarchy and egalitarian worldview policy preferences are positively correlated as individualistic fatalism policy preferences. Although this requires additional empirical testing, it may suggest looking at public views from two main perspectives. While looking for areas of common interest is recommendable, still, the question arises to what extent are expected groups to agree on all aspects of such strategy. While a combination of policy instruments may be more coherent to resonate with the general public preference, cultural worldviews are also dynamic and open to be influenced with persuasive messages to dispel differences and stimulate more educated decision-making.

\subsection{Limitations and future research directions}

Although our study shows a strong link between cultural worldviews and sustainable land use policy preferences, it has some limitations. Our finding that fatalism is negatively associated with market-based policy preference which is contrary to what one would expect based on the cultural theory of risk proposition may spur further research into whether the different worldview rationalities may be expressed differently or in a consistent fashion in different countries. Also, our finding that hierarchy and egalitarian policy preferences are positively correlated as individualistic and fatalism policy preferences, calls for additional empirical testing on the plurality of policy preferences for different cultural worldviews. Our sample was residents in the Puntland state, and therefore the citizens in the other states may have different policy preferences. Apart from these limitations, our findings are appropriate for policymaking.

\section{Conclusion}

This study provides quantitative information that Somali citizens in Puntland state are willing to consent to sustainable land use policies as opposed to the status quo and contributes to how people with commonly polarized worldviews are likely to react to different policy instruments. Cultural worldviews are important predictors of land use policy preferences. People with different cultural worldviews prefer different policy instruments and no single policy instrument is sufficient to significantly augment approval from the general public. While these important differences highlight the challenge of designing policies that can resonate across people with polarized worldviews, our findings also demonstrate that there is a middle ground for efforts to dispel disagreement and hence can be base for designing policies that can appeal to citizens of different worldviews simultaneously to promote broader public preference. In this regard, hierarchy and egalitarian policy preferences are positively correlated as individualistic and fatalistic policy preferences are. Therefore, the patterns of cultural worldviews policy preferences can be seen from two broad worldview perspectives. These two perspectives can then be involved at the center of policy debate to lessen the differences even if it doesn't make specific policies capture holistic preference. In other words, policy design should creatively incorporate the different ways that these two broad cultural worldview perspectives perceive and interpret social-environmental relations into policy decisions to achieve sustainable policy outcomes. This may require raising environmental awareness to elicit voluntary action, allocate funds to compensate for pro-environmental behaviors, and pass laws to restrict and punish unlawful practices.

\section{Funding}

This work was supported by the Chinese Academy of Sciences (CAS) and the Alliance of International Science Organizations (ANSO) (2020D054).

\section{Conflict of interest}

The authors report no potential conflict of interest

\section{Acknowledgments}

The authors would like to thank the anonymous reviewers for providing constructive comments that improved the manuscript. 
Appendix 1. Statements to elicit socio-cultural biases (worldviews)

\section{Egalitarianism}

The natural environment is delicate.

The balance can easily be broken.

The environment cannot recover if we push beyond it beyond what it cope and we all can have a social duty to conserve the environment.

Hierarchy

The conservation of the natural environment should be the responsibility of the government and scientists only.

People should obey environmental regulations irrespective of whether they consider them fair.

If we obey environmental laws and policies, the environment will stay safe.

\section{Individualism}

The natural environment is full of resources for human use.

People should have freedom of choice irrespective of environmental impacts.

The most reasonable way in environmental conservation is free competitiveness and deregulation.

Fatalism

The natural environment functions in unpredictable ways.

People can do nothing to conserve the natural environment.

Environmental laws are just a means of regulating people and usually fail.

\section{Appendix 2. Description of the policies}

The Somali government is considering implementing different land use policies-actions that are meant to reduce deforestation and land degradation. The government wants to know which policy strategy people would like to accept. Please read these strategies carefully and choose the one you most prefer.

\section{1) Regulatory}

In this policy, the government wants to decide the specific land uses of the country such as the sites of new villages, roads, and farms, and penalize anyone who does not obey, to impose regulations concerning land conversion and protection of trees, to control the development of land into the prime forests and farmlands.

2) Market-based

In this policy, the government plans to reward communities that protect the natural vegetation in their respective areas, plant trees, and avoid land clearing, reward the pastoralists, who adapt sustainable grazing, and give subsidies to the households that use clean energy and avoid charcoal consumption.

\section{3) Informational}

In this policy, the government will educate the citizens about ecosystem services and the negative effects of deforestation in schools, through televisions, radios, and other means of communication to discourage tree cutting and charcoal consumption in households, encourage businesses to lower gas utility bills, and other clean energy as a substitute for charcoal consumption and relies upon people to voluntarily use the land sustainably by following the given code of conduct and recommendations.

4) Lack of policy instruments (status-quo)

In this way, the government can also leave the land and forests alone and not intervene in charcoal production because some people get income; therefore, their livelihoods are more important than the trees.

Please, which of these four policy strategies would you prefer to accept?

1) Regulatory

2) Market-based

3) Informational

4) No policy

\section{References}

Alix-Garcia, J.M., Sims, K.R.E., Orozco-Olvera, V.H., Costica, L.E., Fernández Medina, J. D., Monroy, S.R., 2018. Payments for environmental services supported social capital while increasing land management. Proc. Natl. Acad. Sci. USA 115 (27), 7016-7021. https://doi.org/10.1073/pnas.1720873115.

Bateman, I.J., Carson, R.T., Day, B., Hanemann, M., Hanley, N., Hett, T., Pearce, D.W., 2002. Economic Valuation with Stated Preference Techniques: A Manual.

Batunacun, Wieland, R., Lakes, T., Yunfeng, H., Nendel, C., 2019. Identifying drivers of land degradation in Xilingol, China, between 1975 and 2015. Land Use Policy 83, 543-559. https://doi.org/10.1016/j.landusepol.2019.02.013.

Bayard, B., Jolly, C., 2007. Environmental behavior structure and socio-economic conditions of hillside farmers: a multiple-group structural equation modeling approach. Ecol. Econ. 62 (3-4), 433-440. https://doi.org/10.1016/j. ecolecon.2006.07.004.

Böcher, M., 2012. A theoretical framework for explaining the choice of instruments in environmental policy. For. Policy Econ. 16, 14-22. https://doi.org/10.1016/j. forpol.2011.03.012.

Böcher, M., Töller, A.E., 2007. Instrumentenwahl und Instrumentenwandel in der Umweltpolitik: ein theoretischer Erklärungsrahmen. Polit. Umw. 299-322.

Böcher, M., Töller, A.E., 2003. Conditions for the emergence of alternative environmental policy instruments. In: Proceedings of the Paper Presented at the 2nd ECPR-Conference.

Bolognesi, M., Vrieling, A., Rembold, F., Gadain, H., 2015. Rapid mapping and impact estimation of illegal charcoal production in southern Somalia based on WorldView-1 imagery. Energy Sustain. Dev. 25, 40-49. https://doi.org/10.1016/j. esd.2014.12.008.

Borrás, S., Edquist, C., 2013. The choice of innovation policy instruments. Technol. Forecast. Soc. Chang. 80 (8), 1513-1522. https://doi.org/10.1016/j. techfore.2013.03.002.

Bruggeman, D., Meyfroidt, P., Lambin, E.F., 2015. Production forests as a conservation tool: effectiveness of Cameroon's land use zoning policy. Land Use Policy 42, 151-164. https://doi.org/10.1016/j.landusepol.2014.07.012.

Bruggeman, D., Meyfroidt, P., Lambin, E.F., 2018. Impact of land-use zoning for forest protection and production on forest cover changes in Bhutan. Appl. Geogr. 96, 153-165. https://doi.org/10.1016/j.apgeog.2018.04.011.

Burstein, P., 2003. The impact of public opinion on public policy: a review and an agenda. Political Res. Q. 56 (1), 29-40.

Carson, R.T., 2000. Contingent Valuation: A User's Guide. ACS Publications.

Cherry, T.L., Kallbekken, S., Kroll, S., 2017. Accepting market failure: cultural worldviews and the opposition to corrective environmental policies. J. Environ. Econ. Manag. 85, 193-204. https://doi.org/10.1016/j.jeem.2017.05.004.

Cole, D.H., Grossman, P.Z., 2002. Toward a Total-Cost Approach to Environmental Instrument Choice an Introduction to the Law and Economics of Environmental Policy: Issues in Institutional Design. Emerald Group Publishing Limited.

Dake, K., 1992. Myths of nature: culture and the social construction of risk. J. Soc. Issues 48 (4), 21-37.

Douglas, M., 1970. Natural Symbols: Explorations in Cosmology. Taylor \& Francis Ltd, London.

Douglas, M., Wildavsky, A, 1983. Risk and Culture: An Essay on the Selection of Technological and Environmental Dangers. University of California Press.

Grammatikopoulou, I., Badura, T., Vačkárová, D., 2020. Public preferences for post 2020 agri-environmental policy in the Czech Republic: a choice experiment approach. Land Use Policy 99, 104988.

de Groot, J.I.M., Schuitema, G., 2012. How to make the unpopular popular? Policy characteristics, social norms and the acceptability of environmental policies. Environ. Sci. Policy 19-20, 100-107. https://doi.org/10.1016/j.envsci.2012.03.004.

Gunningham, N., Sinclair, D., 2003. Leaders and laggards: next-generation environmental regulation. Manag. Environ. Qual. Int. J.

Halik, A., Verweij, M., 2018. Socio-cultural diversity and public preferences for coral reef management options in Indonesia. Ocean Coast. Manag. 162, 13-23.

Hartmann, T., 2012. Wicked problems and clumsy solutions: planning as expectation management. Plan. Theory 11 (3), 242-256.

Hensher, D.A., Rose, J.M., Rose, J.M., Greene, W.H., 2005. Applied Choice Analysis: A Primer. Cambridge University Press.

Jama, O.M., Liu, G., Diriye, A.W., Yousaf, B., Basiru, I., Abdi, A.M., 2020. Participation of civil society in decisions to mitigate environmental degradation in post-conflict societies: evidence from Somalia. J. Environ. Plan. Manag. 0 (0), 1-21. https://doi. org/10.1080/09640568.2019.1685957. 
Jordan, A., Wurzel, R., Zito, A.R., Brückner, L., 2003. European governance and the transfer of 'new' environmental policy instruments (NEPIs) in the European Union. Public Adm. 81 (3), 555-574.

Kaczan, D., Pfaff, A., Rodriguez, L., Shapiro-Garza, E., 2017. Increasing the impact of collective incentives in payments for ecosystem services. J. Environ. Econ. Manag. 86, 48-67. https://doi.org/10.1016/j.jeem.2017.06.007.

Kahan, D.M., Braman, D., 2006. Cultural cognition and public policy. Yale Law Policy Rev. 24, 149.

Kemper, N.P., Popp, J.S., Nayga, R.M., Kerr, J.B., 2018. Cultural worldview and genetically modified food policy preferences. Food Policy 1-16. https://doi.org/ 10.1016/j.foodpol.2018.09.003.

Lambin, E.F., Meyfroidt, P., Rueda, X., Blackman, A., Bo, J., Cerutti, P.O., Wunder, S. 2014. Effectiveness and synergies of policy instruments for land use governance in tropical regions. Glob. Environ. Change 28, 129-140. https://doi.org/10.1016/j. gloenvcha.2014.06.007.

Lasisi, T.T., Eluwole, K.K., Alola, U.V., Aldieri, L., Vinci, C.P., Alola, A.A., 2021. Do tourism activities and urbanization drive material consumption in the OECD countries? A quantile regression approach. Sustainability 13 (14), 7742.

Leiserowitz, A., 2006. Climate change risk perception and policy preferences: the role of affect, imagery, and values. Clim. Chang. 77 (1-2), 45-72. https://doi.org/10.1007/ s10584-006-9059-9.

Makrickiene, E., Brukas, V., Brodrechtova, Y., Mozgeris, G., Sedmák, R., Šálka, J., 2019. From command-and-control to good forest governance: a critical interpretive analysis of Lithuania and Slovakia. For. Policy Econ. 109, 102024 https://doi.org/ 10.1016/j.forpol.2019.102024.

Malik, K., Rahman, S.M., Khondaker, A.N., Abubakar, I.R., Aina, Y.A., Hasan, M.A., 2019. Renewable energy utilization to promote sustainability in GCC countries: policies, drivers, and barriers. Environ. Sci. Pollut. Res. 26 (20), 20798-20814.

Mamadouh, V., 1999. Grid-group cultural theory: an introduction. GeoJournal 47 (3), 395-409.

Markle, G., 2019. Understanding pro-environmental behavior in the US: Insights from grid-group cultural theory and cognitive sociology. Sustainability 11 (2), 532. https://doi.org/10.3390/su11020532.

McFadden, D., 1974. Analysis of qualitative choice behavior. Front. Econ. 1, 105-142.

Mitchell, R.C., Carson, R.T., Carson, R.T., 1989. Using Surveys to Value Public Goods: The Contingent Valuation Method. Resources for the Future, Washington DC.

O'Riordan, T., Jordan, A., 1999. Institutions, climate change and cultural theory: towards a common analytical framework. Glob. Environ. Chang. 9 (2), 81-93.

Oduori, S.M., Rembold, F., Abdulle, O.H., Vargas, R., 2011. Assessment of charcoal driven deforestation rates in a fragile rangeland environment in North Eastern Somalia using very high resolution imagery. J. Arid Environ. 75 (11), 1173-1181. https://doi.org/10.1016/j.jaridenv.2011.05.003.

Omuto, C.T., Balint, Z., Alim, M.S., 2011. A framework for national assessment of land degradation in the drylands: a case study of somalia. Land Degrad. Dev. 25 (2), 105-119. https://doi.org/10.1002/ldr.1151.

Pleger, L.E., 2017. Voters' acceptance of land use policy measures: a two-level analysis. Land Use Policy 63, 501-513. https://doi.org/10.1016/j.landusepol.2017.02.001.

Price, J.C., Walker, I.A., Boschetti, F., 2014. Measuring cultural values and beliefs about environment to identify their role in climate change responses. J. Environ. Psychol. 37, 8-20. https://doi.org/10.1016/j.jenvp.2013.10.001.

Reinikainen, J., Sorvari, J., Tikkanen, S., 2016. Finnish policy approach and measures for the promotion of sustainability in contaminated land management. J. Environ. Manag. 184, 108-119. https://doi.org/10.1016/j.jenvman.2016.08.046.

Rembold, F., Oduori, S.M., Gadain, H., Toselli, P., 2013. Mapping charcoal driven forest degradation during the main period of al shabaab control in southern somalia. Energy Sustain. Dev. 17 (5), 510-514. https://doi.org/10.1016/j.esd.2013.07.001.

Rissman, A.R., Kohl, P.A., Wardropper, C.B., 2017. Public support for carrot, stick, and no-government water quality policies. Environ. Sci. Policy 76, 82-89. https://doi. org/10.1016/j.envsci.2017.04.012.
Schwarz, M., Thompson, M., 1990. Divided We Stand: Redefining Politics, Technology, and Social Choice. University of Pennsylvania Press.

Shoyama, K., Managi, S., Yamagata, Y., 2013. Public preferences for biodiversity conservation and climate-change mitigation: a choice experiment using ecosystem services indicators. Land Use Policy 34, 282-293.

Sims, K.R.E., Alix-Garcia, J.M., 2017. Parks versus PES: evaluating direct and incentivebased land conservation in Mexico. J. Environ. Econ. Manag. 86, 8-28. https://doi. org/10.1016/j.jeem.2016.11.010.

Stadelmann-Steffen, I., 2011. Citizens as veto players: climate change policy and the constraints of direct democracy. Environ. Polit. 20 (4), 485-507. https://doi.org/ 10.1080/09644016.2011.589577.

Thompson, M., Ellis, R., Wildavsky, A., 1990. Cultural Theory. Westview Press, Boulder, Colo.

Tisdell, C., Wilson, C., 2006. Information, wildlife valuation, conservation: experiments and policy. Contemp. Econ. Policy 24 (1), 144-159.

UNDP, 2012. Energy Alternatives to Charcoal Production: Findings and Proposals.

Unep, 2005. The State of the Environment in Somalia: A Desk Study. 〈http://wedocs. unep.org/bitstream/handle/20.500.11822/8425/State_of_environment_Somalia.pd $\mathrm{f}$ ? sequence $=3 \&$ is Allowed $=\mathrm{y}\rangle$.

UNFPA, 2014. Population Estimation Survey 2014.

Upton, V., Dhubháin, Á.N., Bullock, C., 2012. Preferences and values for afforestation: the effects of location and respondent understanding on forest attributes in a labelled choice experiment. For. Policy Econ. 23, 17-27.

USAGM, 2013. Media Use in Somalia. United States Agency for Global Media/Gallup, Washington, DC.

Valeri, E., Gatta, V., Teobaldelli, D., Polidori, P., Barratt, B., Fuzzi, S., Maione, M., 2016. Modelling individual preferences for environmental policy drivers: empirical evidence of Italian lifestyle changes using a latent class approach. Environ. Sci. Policy 65, 65-74.

Van Gossum, P., Ledene, L., Arts, B., De Vreese, R., Van Langenhove, G., Verheyen, K., 2009. New environmental policy instruments to realize forest expansion in Flanders (northern Belgium): a base for smart regulation? Land Use Policy 26 (4), 935-946. https://doi.org/10.1016/j.landusepol.2008.11.005.

Van Rijnsoever, F.J., Van Mossel, A., Broecks, K.P., 2015. Public acceptance of energy technologies: the effects of labeling, time, and heterogeneity in a discrete choice experiment. Renew. Sustain. Energy Rev. 45, 817-829.

Vedung, E., Rist, R.C., Bemelmans-Videc, M.-L., 1998. Carrots, Sticks \& Sermons: Policy Instruments and Their Evaluation. Transaction Publishers.

Verweij, M., Douglas, M., Ellis, R., Engel, C., Hendriks, F., Lohmann, S., Thompson, M., 2006. Clumsy solutions for a complex world: the case of climate change. Public Adm. 84 (4), 817-843.

Waaben Thulstrup, A., Habimana, D., Joshi, I., Mumuli Oduori, S., 2018. Uncovering the challenges of domestic energy access in the context of weather and climate extremes in Somalia. Weather Clim. Extrem., 100185 https://doi.org/10.1016/j. wace.2018.09.002, 100185-100185.

Wildavsky, A., 1987. Choosing preferences by constructing institutions: a cultural theory of preference formation. Am. Political Sci. Rev. 81, 3-22.

Williams, K.J.H., 2014. Public acceptance of plantation forestry: implications for policy and practice in Australian rural landscape. Land Use Policy 38, 346-354. https://doi. org/10.1016/j.landusepol.2013.11.023.

Wunder, S., Engel, S., Pagiola, S., 2008. Taking stock: a comparative analysis of payments for environmental services programs in developed and developing countries. Ecol. Econ. 65 (4), 834-852. https://doi.org/10.1016/j. ecolecon.2008.03.010.

Xue, W., Hine, D.W., Loi, N.M., Thorsteinsson, E.B., Phillips, W.J., 2014. Cultural worldviews and environmental risk perceptions: A meta-analysis. J. Environ. Psychol. 40, 249-258. 